\title{
Health Risks Associated with Visiting Friends and Relatives in Developing Countries
}

\author{
M artha Fulford, M D, M A, FRCPC, and Jay S. Keystone, M D, M SC (CTM ), FRCPC*
}

\begin{abstract}
Address
*University of Toronto; Toronto General Hospital, 200 Elizabeth Street 9ES-411A, Toronto, 0 ntario M5G 2C 4, Canada.

E-mail: jay.keystone@ utoronto.ca
\end{abstract}

Current Infectious Disease Reports 2005, 7:48-53

Current Science Inc. ISSN 1523-3847

Copyright @ 2005 by Current Science Inc.

An increasingly large proportion of immigrants to developed countries is arriving from less developed countries in Africa, Asia, and Latin America. W hen these immigrants return to their country of origin to visit friends and relatives, they are at high risk of acquiring tropical infections, compared with other travelers. Immigrants who return to their country of origin to visit friends and relatives (VFRs) are more likely to travel to rural areas for long periods of time, to consume contaminated food and beverages, and to have more prolonged, intimate contact with local populations. As a group, they are less likely to seek pretravel advice or take antimalarial chemo prophylaxis. This article discusses the increased risk of tuberculosis, malaria, foodand waterborne illnesses, hepatitis A, and HIV and other sexually transmitted infections in VFRs.

\section{Introduction}

In 1990, 9\% of the population of theUnited States were firstgeneration immigrants; by the year 2000, this had increased to more than $12 \%$ or almost 35 million people If one al so takes into consideration the children of first-generation immigrants, they make up almost $20 \%$ of the American population. In Canada, the percentage of the population that was foreign born in 2000 was 19\%. Worldwide, the number of people living outside their birth country was 175 million-more than twice the number since 1970 [1]. In cities such as Miami, Los Angel es, and Toronto, Canada, almost $50 \%$ of the population is foreign born [2].

Despite comprising a minority (albeit a significant minority) of the population of developed countries, immigrants accounted for a disproportionately large number of international air travelers. In 2002, 38\% of passengers on outbound flights from the United States were immigrants [3]. Forty percent of the trips from the United Kingdom to
Africa in 2000 weretaken by immigrants [4 • •]. Overall, $25 \%$ of travelers from major European airports were immigrants returning to their country of origin [5]. When immigrants return to their home country, it is often to visit friends and relatives

There are specific health issues that are related to immigration. On arrival in their host countries, immigrants often have high rates of infectious diseases such as tubercul osis, intestinal parasites, viral hepatitis, sexually transmitted infections (STIs), and malaria [6•]. Likewise, when immigrants travel back to their country of origin, they are at increased risk for health complications, compared with other travelers. This article focuses on several of the specific travel-related infectious disease issues associated with immigrants who return to their country of origin to visit friends and relatives (VFRs), and ind udes children of VFRs.

\section{Heal th Risks in Those Returning to Their Country of Origin to Visit Friends and Relatives}

There are few data available regarding VFRs as a specific group. One of the difficulties is that wehaveno standardized definition for this group. A variety of terms have been used to describe this group, including immigrants, migrants, and foreign born. Refugees and displaced persons may also be included. The children of VFRs, often born in the host country, are likely to be ind uded in studies of VFRs. It can be difficult to compare studies because the population groups included may vary significantly depending on the definition used and on how the group was identified for study. In general, we are referring to ethnic travelers and their children who have immigrated but continue to have links with family and friends in their country of origin [ $7 \bullet \cdot$ ]. However, al though we have defined the group we are interested in, identifying the specific reason for travel may be a challenge Many travelers list more than one reason for their trip and may be combining tourism with a visit to friends and relatives $[5,8]$. Studies may not al ways captureall VFRs.

There has been a shift in immigration patterns from a predominance of European migrants to those from more tropical regions such as Asia, Africa, and Central and Latin America, and there has been a matching increase in travel 
back to these areas. These shifting trends in the travel destinations of VFRs bring with them an increased risk of acquiring tropical infections $[7 \cdot \bullet]$.

Those who return to their country of origin to visit friends and relatives are likely to take greater risks and have increased exposures, compared to native-borne travelers from developed countries. Travel is morelikely to be undertaken at the last minute in order to attend family events such as marriages or funerals or to visit ill relatives. VFRs are more likely to travel with small children or while pregnant. They are also less likely to be deterred by pre-existing medical problems [2]. Once at their destination, most VFRs stay with family. This close contact with local population increases the risk of exposure to illnesses such as tuberculosis, hepatitis A and B, and meningitis. They are more likely to be visiting rural locations where mal aria is readily transmitted, eating contaminated local food and drinking unpurified water, and using local transportation. These are all factors that increase the risk of exposure to an infectious disease or other medical problem such as trauma from a motor vehicle accident.

Despite their frequency of travel, VFRs as a group are less likely to seek pretravel advice Van Herck et al. [5], in their survey of travelers departing from European airports, note that $52 \%$ had sought travel health advice, compared with only $31 \%$ of VFRs. A similar Canadian study of 307 VFRs departing for India showed that only $31 \%$ planned on using malaria chemoprophylaxis, less than $10 \%$ intended on using personal protective measures to prevent mosquito bites, and only $7 \%$ had been prescribed an appropriate antimalarial medication [9].

Language and cultural barriers may prevent VFRs from seeking medical advice. Pretravel health advice is often not covered by national heal th services and therefore cost is often a significant barrier. VFRs may not be aware of the need for pretravel health advice or of their increased risk for infectious diseases [8]. They may bel ieve they are immune to infectious diseases of their homeland and therefore do not require protection $[4 \cdot \bullet, 10]$. For some viral infections such as hepatitis A and Japanese encephalitis, this belief may be correct. However, many infections, such as malaria and typhoid fever, do not confer longlasting immunity. Furthermore, over time infections such as hepatitis A may decrease locally as the standard of living improves, whereas others, such as malaria, may increase because of drug resistance and environmental changes. Their belief that they are not at risk of travel-related infectious diseases may be extended to their children, who are often born in the new host country. These children, with no previous exposure, will have no immunity to these infections and are particularly vulnerable Some VFRs who have concerns regarding immigration status may be reluctant or have difficulty accessing the health care system.

Of those who did seek pretravel advice, a variety of sources were consulted, ind uding travel agents, the Internet, and family and friends. When a health care professional was seen, it was usually a general practitioner (GP) $[5,9]$. Unfortunately, the advice given by GPs may not al ways be up to date, as has been evidenced by incorrect advice regarding mal aria chemoprophylaxis $[10,11]$.

Although VFRs make up less than $50 \%$ of international travel ers, they account for a significant proportion of illreturned travelers. The following text discusses several of the more common infections seen in VFRs for which we have reasonable data: tuberculosis, malaria, food- and waterborne illnesses, hepatitis, HIV, and other STIs. We also briefly discuss some of the possible epidemiologic implications of infections in this group of travelers.

\section{Tuberculosis}

It is estimated that more than one third of the world's population is infected with M ycobacterium tuberculosis. Immigrants have previously been identified as a high risk group for the devel opment of symptomatic tuberculosis often within the first 5 years after immigration. One study screening immigrants in Spain found that $44 \%$ were positive for latent tubercul osis [12]. Screening of refugees arriving in Minnesota in 1997 found that 35\% tested positive for latent tuberculosis. From 1992 to 1997, the overall rates of tuberculosis in the United States decreased by $26 \%$; however, over the same period, the proportion of tuberculosis cases in immigrants increased from $27 \%$ to $39 \%$ [13]. Similar increases in tuberculosis rates have been documented in the United Kingdom, with a dramatic increase of $124 \%$ seen in black Africans and a $20 \%$ increase in immigrants from the Indian subcontinent [14]. In 2001, more than $50 \%$ of cases of active tuberculosis in the United States and in most Western European countries were in foreign-born individuals $[14,15]$.

Travel to and length of time spent in regions with a high rate of tuberculosis are risks for acquisition of the infection [16]. American-born children of immigrants have been shown to have a higher risk of a positive tuberculosis skin test result if they had travel ed to an endemic area within the previous 12 months or if they had hosted a visitor from an endemic area [17].

There are few preventive strategies against tuberculosis. Travelers should be aware of the risk and be cautioned to minimize exposure to individuals who have a cough. Physicians should be aware of the increased risk of tuberculosis in VFRs and screen for it assiduously in this population group. Before travel, VFRs and their children should be given a baseline tuberculin skin test. This should be repeated approximately 3 months after return from an endemic region. Any individual whose skin test result has converted to positive will require a chest radiograph. Individuals with a normal chest radiograph should be offered treatment for latent tuberculosis. If there are changes suggestive of pulmonary tuberculosis, the individual will need full multidrug treatment. 


\section{Malaria}

More than $40 \%$ of the world's population is at risk for mal aria. The World Health Organization (WHO) estimates that there are 300 to 500 million cases and more than 1 million deaths annually from malaria [18]. The annual number of reported cases of malaria in returning travelers is approximately 10,000 , with an estimated mortality of $1 \%$ [19]. However, the actual number of cases is likely two to three times higher because not all cases are reported [20, 21]. Oceania and sub-Saharan Africa are the regions with the highest risk of acquisition of falciparum malaria; most travelers get infected in sub-Saharan Africa.

In 2002 in the United States, 1337 cases of malaria were reported, 849 of which were in divilians; $72 \%$ wereacquired in Africa. The largest proportion of the cases, $45 \%$, was seen in VFRs who had been in malaria-endemic regions [22]. A recent study published from the GeoSentine Surveillance Network showed that VFRs were significantly more likely to present with malaria than were tourists [23]. The surveillance data from TropNetEurop shows that there were 963 cases of malaria in 2003, 831 of which were falciparum. Fifty-five percent of these cases occurred in foreign-born persons living in Europe. From 1985 to 1995, there were 77,683 total cases of malaria reported in Europe [24]. The data are cumulative with little breakdown provided regarding the background of the cases. An exception is Italy that noted an increase in imported malaria in immigrants from $14 \%$ in 1986 to $40 \%$ in 1991 . This increase was attributed to an increase in the number of African immigrants and a consequent increase in the number of trips back to visit their country of origin [25].

A review of pediatric patients seen in London between 1996 and 2001 identified 211 cases. Eighty-two percent (173 cases) were seen in children living in the United Kingdom who had traveled to a malaria-endemic country. All of the children were ethnic minorities; 123 were of black African descent. All were traveling in order to visit family in their parents' country of origin. The remaining $18 \%$ of malaria cases were seen in children visiting the United Kingdom from malarial regions. Malaria chemoprophylaxis was being taken by $42 \%$ of the children traveling to endemic areas. Of this group, only $15 \%$ were taking a recommended regimen [10]. A retrospective analysis of children hospitalized for malaria in Toronto, Canada identified 72 children, of whom 31 were VFRs and 34 were immigrants. All of the children who met the WHO criteria for severe falciparum malaria were VFRs or immigrants. Fifty-eight percent of the children had received pretravel antimalarial advice, but only $16 \%$ were actually taking recommended regi mens [26].

Those who return to their country of origin to visit friends and relatives often travel during the Northern Hemisphere's summer months, which coincide with the rainy season in West Africa and with themonsoon season in the Indian subcontinent. These are seasons of high malaria transmission. VFRs are more likely to be traveling to rural areas and to be staying for long periods of time. They commonly believe they are immune to malaria $[4 \bullet \bullet, 10,27]$. This is a belief that extends to their children, regardless of where they were born. Although individuals living in endemic zones can devel op a partial immunity, this is not an immunity that persists for life Ongoing immunity is dependent on regular reexposure to malaria. Immigrants who are living in nonmalarial regions will lose their immunity and are at high risk of developing symptomatic malaria when traveling "home." Children of immigrants who are born in their host country have no immunity to mal aria and are highly vul nerable to infection.

As discussed earlier, VFRs often do not seek pretravel advice. When advice is sought, it is morelikely to be from a GP who may not be up to date on pretravel recommendations. VFRs often seek physicians from their own ethnic background who may share the belief that they do not require malaria chemoprophylaxis [28]. Cost may be an impediment to taking antimalarials. In some cases, VFRs may decide to purchase drugs once they have arrived at their destination. Drugs purchased in developing countries may be substandard. Some preparations of chloroquine tested in Nigeria and Thailand were found to contain no active ingredient [29].

There is clear evidence that VFRs are at high risk of devel oping malaria, and there is also evidence showing that, as a group, they are less likely to use malaria chemoprophylaxis. There are few data available regarding the use of barrier precautions and chemical insecticides by VFRs. However, the information available is not encouraging. In the Canadian airport study by dos Santos et al. [9], less than $10 \%$ of travelers planned to use any method to minimize the risk of a mosquito bite. A French study reviewed the antimalarial methods used by 88 children admitted to hospital with malaria. They reported al most two thirds used bednets, but only $15 \%$ showed good compliance Only $38 \%$ of the bednets were impregnated with insecticide [30].

Bacaner et al. [4・•] recently published recommendations for provision of pretravel advice to VFRs, including disseminating information about travel medicine services in ethnic media, offering travel medicine service in the primary care clinics frequented by immigrants, and using medically trained, cross-cultural interpreters. Travel agencies could al so be targeted as a place for provision of information. Pamphlets in various languages could be made available to travel ers to high-risk malaria regions. Given the increased use of the Internet for making travel arrangements, links on some of the more popular webbooking sites to government-approved travel information sites might be another strategy for increasing awareness among travelers. 


\section{Food- and Waterborne IIInesses}

The most common illness to affect travelers to developing countries is traveler's diarrhea (TD). Attack rates from $20 \%$ to $66 \%$ have been described [31]. These usually occur during the first 2 weeks of stay. TD tends to be a selflimited disease lasting 1 to 4 days. Fecal contamination of food and drinks is the cause of most cases, with enterotoxigenic Escherichia coli being the most commonly identified pathogen. There are few data specifically regarding uncomplicated TD in VFRs. However, there are good data avail able regarding typhoid fever, which is also spread by fecal contamination of food or drink. It is reasonable to assume that rates of infection similar to those seen with typhoid fever would be seen with other gastrointestinal pathogens because the risk factors for transmission are the same. A recent review of typhoid fever in the United States examined all laboratory-confirmed cases of acute Salmonella enterica subtypetyphi from 1994 to 1999. Recent travel was reported in $74 \%$ of cases, with only $4 \%$ having received prior vaccination. Fifty-three percent of the travelassociated cases were in foreign-born individuals; $80 \%$ of those who reported a reason for their travel were VFRs [32 • ]. A prior review of reported cases of typhoid fever in the United States from 1985 to 1994 found that $77 \%$ were in VFRs [33]. A study of typhoid cases in northwest England found that all of the typhoid cases examined over a 2-year period were travel-related [34]. Overall, most cases of typhoid fever in travelers were acquired in the Indian subcontinent, including Pakistan, India, and Bangladesh, with reported rates ranging from $37 \%$ to $91 \%[7 \cdot \bullet, 35]$.

The advice "boil it, cook it, peel it, or forget it" has proven impossible for most travel ers to adhere to as they succumb to temptations such as generous buffets, fresh salads, and ice cold drinks [31,36]. These recommendations may be even more difficult for VFRs to follow because they are likely to be house guests with less control over what foods they are served. There are a variety of traditional foods that carry particular risks, such as unpasteurized soft cheeses (queso fresco) in Latin America or raw fish (cevichein Latin America; sushi in Asia), which should be avoided. It may be more val uable to emphasize prevention measures such as frequent hand washing, the use of hand-sanitizing solutions, and boiling of drinking water. VFRs who are traveling with young children should be routinely provided with instructions for home-made oral rehydration solution. Immunization against typhoid fever should be considered for VFRs, particularly those traveling to the Indian subcontinent.

\section{Hepatitis A}

Hepatitis $A$ is one of the most common vaccinepreventable travel-related infections [37]. It is transmitted through fecal contamination of food and beverages and usually causes a self-limited illness. However, in those aged older than
50 years, it has a mortality rate of $2.7 \%$. Hepatitis A is the cause of approximately $50 \%$ of cases of acute hepatitis in North America. Five percent to $20 \%$ of cases have travel identified as a risk. In a study examining cases of hepatitis $A$ in the United Kingdom, Behrens [ $7 \bullet \cdot$ ] and Behrens et al. [38] found that ethnic travelers were eight times more likely to acquire hepatitis $A$ than were other travel ers. Children aged younger than 15 years had the highest risk. An autumn increase in reported rates of hepatitis A was noted in the Netherlands, initially in children of Turkish and Moroccan descent who acquired their infection whiletraveling over the summer. A second peak was then noted in cases acquired in the Netherlands, presumably from secondary transmission $[7 \bullet \cdot 39]$. A recent study examining rates of hepatitis $A$ from 1998 to 2000 in Hispanic children living al ong theUS Mexico border determined that travel to Mexico was associated with acquisition of infection [40].

Previously, immigrants born in hepatitis A-endemic countries who emi grated after the age of 20 years al most certainly had an acquired immunity. A study of 129 VFRs attending a pretravel clinic in Boston found that 95\% were immune [41]. A prevalence study undertaken in the Netherlands showed an overall seropreval ence rate of $33.8 \%$, with those of Turkish or Moroccan descent having morethan $90 \%$ seropositivity [42]. However, the epidemiology of hepatitis $A$ is changing. As socioeconomic standards improve in devel oping countries, the rates of hepatitis $A$ seropreval ence are decreasing. One study in Latin America showed that anywhere from $20 \%$ to $70 \%$ of youth had no immunity. In India, Das et al. [43] showed that $41 \%$ of outpatients aged between 25 and 34 years at a New Delhi clinic were susceptible to hepatitis A. Therefore, those who immigrated when they were aged younger than 10 years can no longer be considered immune. The children of VFRs born in their host country will have rates of seroprevalence similar to those seen in the general population. Such travelers should be administered the hepatitis $A$ vaccine before departure Vaccination will prevent disease in VFRs and also prevent dissemination of infection into the local population after their return to their host country.

\section{HIV and Sexually Transmitted Infections}

There are little published data regarding STIs in VFRs as a specific group. Most of the available data examine rates of STIs in immigrants. Data on HIV acquisition in the United Kingdom to March 2004 showed that 21,875 cases were acquired through heterosexual contact. Of these, 15,281 were acquired in Africa. The proportion of cases acquired through heterosexual contact has been increasing since 1999, and the majority of the cases were acquired overseas [44]. Fenton et al. [45] did a cross-sectional survey of 756 black Africans living in London. Travel to their home country had been undertaken by $43 \%$ of the men and $46 \%$ of the women. Forty percent of the men and $21 \%$ of the women indicated they had acquired a new sexual partner 
while away. Forty-two percent indicated that they had not used a condom during their last sexual intercourse. Respondents who had previous STIs and who had more than five sexual partners in the previous year were more likely to have acquired a new sexual partner while abroad. A report on an outbreak of syphilis in the United Kingdom in 2003 to 2004 identified 1775 cases. Most of the cases were in men who have sex with men. There were 370 cases in heterosexual males and 222 in women. Of these, $23 \%$ were acquired outside of the United Kingdom, with al most $50 \%$ of the cases in people from the Caribbean or Africa [46]. Overall, $14 \%$ to $25 \%$ of gonorrhea and syphilis cases diagnosed in Europe were acquired abroad. These data are for all travelers and not specific to VFRs; however, they do draw attention to the role of travelers in the local spread of STIs [31]. This rai ses significant public heal th issues that are of concern, such as the potential introduction of antibiotic-resistant strains of infections. In Asia, up to $40 \%$ of all strains of $\mathrm{N}$ eisseria gonorrhoeae are resistant to quinolones. These strains were initially introduced into the United States by travelers but have now become endemic in California and Hawaii [47]. In North America and Europe, there is one main subtype of HIV-1 circulating. Infections with other subtypes of HIV brought in by immigrants or travel ers have been documented, which may have implications for the generation of new recombinant viruses [48]. Strategies to attempt to modify sexual behaviors in VFRs while traveling will be a challenge because they will need to focus on individual cultural groups. To date, programs to changesexual behaviors in any particular group have not been a resounding success.

\section{Outbreaks}

With increasing rates of travel and the increasing speed and ease of travel, we have seen increasing spread of infections. One important reason for monitoring the heal th of returning travelers is to prevent local transmission of tropical diseases. Labbe et al. [49] demonstrated that monitoring malaria in returning travel ers is an effective method of monitoring drug-resistant strains. Monitoring the health of returning travelers, and especially that of a high-risk group such as VFRs, is an important public health tool in the prevention of possible outbreaks. Returning travelers may provide an early warning sign of an outbreak in another part of the world. Although not strictly VFRs, Hajj pilgrims from industrialized countries have recently been shown to be at increased risk of meningococcal infection W-135. Despite being immunized before travel, infection was transmitted to household members after return [50]. Our recent experience with severe acute respiratory syndrome demonstrated how quickly an infection can travel around the world. The index case in Toronto was a VFR of Chinese descent and had been in Hong Kong visiting family. The outcome in Toronto, as in much of the world, was the rapid and frightening spread of a novel coronavirus [51].

\section{Conclusions}

In recent years, immigrants to developed countries have come primarily from devel oping countries that are endemic for a variety of tropical diseases. These immigrants often return to their countries of origin to visit friends and relatives. It has been shown that these VFRs are at increased risk of experiencing travel-related illness. The reasons for their increased risk are multifactorial-they include decreased use of pretravel medical services, decreased use of malarial chemoprophylaxis, increased travel to rural areas, increased time spent with and exposure to local populations, and increased consumption of contaminated local foods and beverages.

In order to decrease the importation of these infections, strategies need to be implemented that will specifically target this high-risk group of travelers. Access to pretravel services needs to be made convenient and inexpensive and must be offered in culturally appropriate ways in a variety of languages. Clinics and heal th care providers that see a large immigrant population need to be recruited for the provision of pretravel advice and for the monitoring and treatment of infections in returned travel ers. This is important for the overall heal th of our immigrant population but also may be of critical importance in the prevention of the spread of these imported diseases in the host countries.

\section{References and Recommended Reading}

Papers of particular interest, published recently, have been highlighted as:

- Of importance

-. Of major importance

1. United Nations: International Migration Report 2002. http://www.un.org/esa/population/publications/ittmig2002/ ittmigrep2002.htm. Accessed August 24, 2004.

2. United Nations: Human Development Report 2004. http:// hdr.undp.org/reports/global/2004. Accessed August 24, 2004.

3. 2002 Profile of U.S. resident travelers visiting overseas destinations. Office of Travel and Tourism Industries, U.S. Department of Commerce. http://tinet.ita.doc.gov/ cat/f-2002-101-001.html. Accessed August 24, 2004.

4. • Bacaner N, Stauffer B, Boulware DR, et al.: Travel medicine considerations for North American immigrants visiting friends and relatives. JAM A 2004, 291:2856-2864.

This is an excellent review of travel medicine issues in VFRs.

5. Van Herck K, Castelli F, Zuckerman J, et al.: Knowledge, attitudes and practices in travel-related infectious diseases: the European Airport Study. J Travel M ed 2004, 11:3-8.

6. Zuckerman JN: Travel medicine. BMJ 2002, 325:26-24. This is a good overview of the evolving field of travel medicine

7.・ Behrens RH: Visiting friends and relatives. In Travel M edicine. Edited by KeystoneJS, Kozarsky PE, Freedman DO, et al.: Spain: Elsevier Ltd.; 2004:281-285.

Thisisa discussion of therisks VFRs have of acquiring infectious diseases The artide focuses on infections for which there are VFR data.

8. Wilder-Smith A, Khairullah NS, Song JH, et al.: Travel health knowledge, attitudes and practices among Australasian travelers. J Travel M ed 2004, 11:9-15.

9. dos Santos CC, Anvar A, Keystone J, Kain K: Survey of use of malaria prevention measures by Canadians visiting India. CM AJ 1999, 160:195-200. 
10. Ladhani S, Bashir H, Patel VS, Shingadia D: Childhood malaria in East London. Pediatr Infect D is J 2003, 22:814-818.

11. Casalino E, Le Bras J, Chaussin F, et al.: Predictive factors of malaria in travelers to areas where malaria is endemic. Arch Intern M ed 2002, 162:1625-1630.

12. Lopez-Velez R, Huerga H, Turrientes MC: Infectious diseases in immigrants from the perspective of a tropical medicine unit. Am J Trop M ed H yg 2003, 69:115-121.

13. Walker PF, Jaranson J: Refugee and immigrant health care. M ed Clin N orth Am 1999, 83:1103-1120.

14. Rose AMC, Watson JM, Graham C, et al.: Tuberculosis at the end of the 20th century in England and Wales: results of a national survey in 1998. Thorax 2001, 56:173-179.

15. World Health Organization: Tuberculosis. http:// www.who.int/mediacentre/factsheets/fs104/en/. Accessed September 2, 2004.

16. Cobelens FGJ, van Deutekom $\mathrm{H}$, Draayer-Jansen IWE, et al.: Risk of infection with Mycobacterium tuberculosis in travelers to areas of high tuberculosis endemicity. Lancet 2000, 356:461-465.

17. Lobato MN, Hopewell PC: Mycobacterium tuberculosis infection after travel to or contact with visitors from countries with a high prevalence of tuberculosis. Am J Respir Crit Care M ed 1998, 158:1871-1875.

18. World Health Organization: Malaria. http://www.who.int/ mediacentre/factsheets/fs094/en/. Accessed September 2, 2004.

19. Loutan L: Malaria: still a threat to travelers. Int J Antimicrob Agents 2003, 21:158-163.

20. Wellems TE, Miller LH: Two worlds of malaria. N Engl J M ed 2003, 349:1496-1498.

21. Kain KC, Harrington MA, Tennyson S, Keystone JS: Imported malaria: prospective analysis of problems in diagnosis and management. Clin Infect D is 1998, 27:142-149.

22. Malaria surveillance--United States, 2002. M M W R M orb M ortal W kly Rep 2004, 53:21-34.

23. Leder K, Black J, O'Brien D, et al.: Malaria in travelers: a review of the Geosentinel Surveillance Network. Clin Infect D is 2004, 391:104-112.

24. Wichmann O, Muhl berger N, Jelinek T: TropNetEurop surveillance data: trends in imported malaria 2003. http://www.eurosurveillanceorg/ew/2004/040624.asp. Accessed September 2, 2004.

25. Muentener $P$, Shdagenhauf $P$, Steffen R: Imported malaria (1985-95): trends and perspectives. Bull World $\mathrm{H}$ ealth $O$ rgan 1999, 77:560-566.

26. Kanani R, Crockett ME, Ford-Jones L, et al.: Imported severe and complicated paediatric malaria at the Hospital for Sick Children, Toronto, 1999-2001 [poster 1127]. Poster presented at the Infectious D iseases Society of America 2004 Annual M eeting. Boston, MA, September 30-October 3, 2004.

27. Schlagenhauf $P$, Steffen R, Loutan L: Migrants as a major risk group for imported malaria in European countries. J Travel Med 2003, 10:106-107.

28. McCarthy M: Should visits to relatives carry a health warning? Lancet 2001, 357:862.

29. Shakoor O, Taylor RB, Behrens RH: Assessment of the incidence of substandard drugs in developing countries. Trop M ed Int H ealth 1997, 2:839-845.

30. Minodier P, Nassur A, Hassid S, et al.: Antimosquito precautions and medical chemoprophylaxis in French children with malaria. J Travel M ed 2003, 10:318-323.

31. Steffen R, deBernardis C, Banos A: Travel epidemiology--a global perspective. Int J Atimicrob Agents 2003, 21:89-95.

32. • SteinbergEB, Bishop R, Hager P, et al.: Typhoid fever in travelers: who should be targeted for prevention? Clin Infect $D$ is 2004, 39:186-191.

This is a review of the risk of acquisition of typhoid fever by travelers and a discussion regarding who should be vaccinated.
33. Mermin JH, Townes JM, Gerber M, et al.: Typhoid fever in the United States, 1985-1994. Arch Intern M ed 1998, 158:633-638.

34. Lighton LL: Follow up in north west England of cases of enteric fever acquired abroad, April 1996 to March 1998. Commun D is Public Health 1999, 2:145-146.

35. Fisher I, Twisselmann B: Surveillance of infection with Salmonella typhi in Europe and the United States. http:// www.eurosurveillance.org/ew/2000/000608.asp. Accessed September 4, 2004.

36. Steffen R, Collard F, Tornieporth N, et al.: Epidemiology, etiology, and impact of traveler's diarrhea in Jamaica. JAM A 1999, 281:811-817.

37. Barnett ED, HolmesAH, Geltman P, et al.: Immunity to hepatitis A in people born and raised in endemic areas. J Travel $M$ ed 2003, 10:11-14.

38. Behrens RH, Collins M, Botto B, Heptonstall J: Risk for British travelers of acquiring hepatitis A. BMJ 1995, 311:193.

39. Termorshuizen F, van de Laar JJ: The epidemiology of hepatitis A in the Netherlands, 1957-1998. N ed Tijdschr Geneeskd 1998, 142:2364-2368.

40. Weinberg M, Hopkins J, Farrington L, et al.: Hepatitis A in Hispanic children who live along the United States-Mexico border: the role of international travel and food-borne exposures. Pediatrics 2004, 114:e68-e73.

41. Bamett ED, HolmesAH, Geltman P, et al.: Immunity to hepatitis A in people born and raised in endemic areas. J Travel $M$ ed 2003, 10:11-14.

42. Termorshuizen F, Dorigo-Zetsma JW, de Melker HE, et al.: The prevalence of antibodies to hepatitis A virus and its determinants in the Netherlands: a population-based survey. Epidemiol Infect 2000, 124:459-466.

43. Das K, Jain A, Gupta S, et al.: The changing epidemiological pattern of hepatitis $A$ in an urban population in India: emergence of a trend similar to the European countries. Eur J Epidemiol 2000, 16:507-510.

44. HIV and AID S in the United Kingdom quarterly update: data to the end of March 2004. http://www.hpa.org.uk/cdr/archive04/ hiv04.htm\#hiv_mar2004. Accessed September 5, 2004.

45. Fenton KA, Chinouya M, Davidson O, Copas A: HIV transmission risk among sub-Saharan Africans in London travelling to their countries of origin. AIDS 2001, 15:1442-1445. http://www.aidsonlinecom/pt/re/aids/fulltext.00002030200107270-00017.htm.

46. Trends in infectious syphilis; update on national data to 2003 and current epidemiological data from the London outbreak. http://www.hpa.org.uk/cdr/PDFfiles/2004/ sti_3104.pdf. Accessed September 5, 2004.

47. Etkind $\mathrm{P}$, RatelleS, George H: International travel and sexually transmitted disease. Emerg Infect D is 2003, 9:1654-1656.

48. Thomson MM, Najera R: Travel and the introduction of human immunodeficiency virus type 1 non-B subtype genetic forms into Western countries. Clin Infect D is 2001, 15:1732-1737.

49. Labbe AC, Patel S, Crandall I, Kain K: Molecular surveillance system of global patterns of drug resistance in imported malaria. Emerg Infect D is 2003, 9:33-36.

50. Wilder-Smith A, Barkham TM, Earnest A, Paton NI: Acquisition of W135 meningococcal carriage in Hajj pilgrims and transmission to household contacts: prospective study. BMJ 2002 , 325:365-366.

51. Poutanen SM, Low DE, Hendry B: Identification of severe acute respiratory syndrome in Canada. N Engl J M ed 2003, 348:1995-2005. 